\title{
Lessons for fisheries management from the EU cod recovery plan
}

Kraak, S.B.M.; Bailey, N.; Cardinale, M.; Darby, C.; Oliveira, J.A.A.; Eero, Margit; Graham, N.; Holmes, S.; Jakobsen, T.; Kempf, A.

Total number of authors:

17

Published in:

Marine Policy

Link to article, DOI:

10.1016/j.marpol.2012.05.002

Publication date:

2013

Link back to DTU Orbit

Citation (APA):

Kraak, S. B. M., Bailey, N., Cardinale, M., Darby, C., Oliveira, J. A. A., Eero, M., Graham, N., Holmes, S., Jakobsen, T., Kempf, A., Kirkegaard, E., Powell, J., Scott, R. D., Simmonds, E. J., Ulirich, C., Vanhee, W., \& Vinther, M. (2013). Lessons for fisheries management from the EU cod recovery plan. Marine Policy, 37, 200213. https://doi.org/10.1016/j.marpol.2012.05.002

\section{General rights}

Copyright and moral rights for the publications made accessible in the public portal are retained by the authors and/or other copyright owners and it is a condition of accessing publications that users recognise and abide by the legal requirements associated with these rights.

- Users may download and print one copy of any publication from the public portal for the purpose of private study or research.

- You may not further distribute the material or use it for any profit-making activity or commercial gain

- You may freely distribute the URL identifying the publication in the public portal 


\title{
Lessons for fisheries management from the EU cod recovery plan
}

\author{
Sarah B. M. Kraak ${ }^{1,2}$, Nick Bailey ${ }^{3}$, Massimiliano Cardinale ${ }^{4}$, Chris Darby ${ }^{5}$, José A. A. \\ De Oliveira ${ }^{5}$, Margit Eero ${ }^{6}$, Norman Graham ${ }^{2}$, Steven Holmes ${ }^{3}$, Tore Jakobsen ${ }^{7}$, \\ Alexander Kempf ${ }^{8}$, Eskild Kirkegaard ${ }^{6}$, John Powell ${ }^{9}$, Robert D. Scott ${ }^{10}$, E. John \\ Simmonds ${ }^{10}$, Clara Ulrich ${ }^{6}$, Willy Vanhee ${ }^{11}$, Morten Vinther ${ }^{6}$
}

\footnotetext{
${ }^{1}$ School of Biological, Earth \& Environmental Sciences, University College Cork, Ireland.

${ }^{2}$ Marine Institute, Rinville, Oranmore, Co. Galway, Ireland.

${ }^{3}$ Marine Scotland Science, Marine Laboratory, 375 Victoria Road, Aberdeen AB11 9DB.

${ }^{4}$ Swedish University of Agricultural Sciences, Department of Aquatic Resources Institute of Marine Research, Lysekil, Sweden.

${ }^{5}$ The Centre for Environment, Fisheries and Aquaculture Science, Pakefield Road, Lowestoft, Suffolk NR33 OHT, United Kingdom.

${ }^{6}$ Technical University of Denmark, National Institute of Aquatic Resources, Charlottenlund, Denmark.

${ }^{7}$ Institute of Marine Research, Bergen.

${ }^{8}$ Johann Heinrich von Thünen Insitute, Institute of Sea Fisheries, Hamburg, Germany.

${ }^{9}$ Countryside and Community Research Institute, Oxstalls Lane, Longlevens, Gloucester GL2 9HW.

${ }^{10}$ European Commission, Joint Research Centre IPSC, Maritime Affairs Unit, TP 051, 21027, Ispra, Italy.

${ }^{11}$ The Institute for Agricultural and Fisheries Research (ILVO), Ankerstraat 1, B-8400 Belgium

*Except for the lead author, authors are listed in alphabetical order.
}

\section{ABSTRACT}

The performance of the EU long-term management plan for cod stocks, in force since 2009, is analysed focusing on the human and institutional factors. The plan operates through landings quotas (TACs) and effort restrictions following a Harvest Control Rule, and deploys a novel instrument allowing Member States to 'buy back' or increase fishing effort for fleet segments engaged in cod-avoidance measures. The stipulated fishing mortality reductions have not been achieved. On the positive side, the 'buy-back' instrument has led to increased uptake of selective gear and implementation of permanent and real-time temporary closures. On the negative side, ignoring the dimension of fishers as reactive agents in the design, the impact assessment, and the annual implementation of the measures has contributed to the failure to adequately implement the plan and achieve its objectives. The main problem is that the landings quotas taken in a mixed fishery did not limit catches because fishers were incentivised to continue fishing and discard overquota catch while quota for other species was available. The effort limitations intended to reduce this effect were insufficient to adequately limit fishing mortality in targeted fisheries, although fishers experienced them as prohibiting the full uptake of other quotas. Recommendations for future plans include (i) management through catch rather than landings quotas, (ii) the internalisation of the costs of exceeding quotas, (iii) use of more selective gear types, (iv) the development of appropriate metrics as a basis for regulatory measures and for evaluations, (v) participatory governance, (vi) fisherybased management, (vii) flexibility in fishing strategy at vessel level.

Keywords: cod recovery plan, fisher responses, Harvest Control Rule, mixed fisheries,results-based management, spatiotemporal measures

*Corresponding author: sarah.kraak@marine.ie Phone +353 (0)91387392.

Article first published online: January 2013

Please note that this is an author-produced PostPrint of the final peer-review corrected article accepted for publication. The definitive publisher-authenticated version can be accesses here:

http://dx.doi.org/10.1016/j.marpol.2012.05.002, (c) 2013 Elsevier 


\section{Lessons for fisheries management from the EU cod recovery plan.}

Sarah B. M. Kraak ${ }^{1,2}$, Nick Bailey ${ }^{3}$, Massimiliano Cardinale ${ }^{4}$, Chris Darby ${ }^{5}$, José A. A. De Oliveira ${ }^{5}$, Margit Eero ${ }^{6}$, Norman Graham ${ }^{2}$, Steven Holmes ${ }^{3}$, Tore Jakobsen ${ }^{7}$, Alexander Kempf $^{8}$, Eskild Kirkegaard ${ }^{6}$, John Powell ${ }^{9}$, Robert D. Scott ${ }^{10}$, E. John Simmonds ${ }^{10}$, Clara Ulrich ${ }^{6}$, Willy Vanhee ${ }^{11}$, Morten Vinther ${ }^{6}$

Except for the lead author, authors are listed in alphabetical order.

1. School of Biological, Earth \& Environmental Sciences, University College Cork, Ireland.

2. Marine Institute, Rinville, Oranmore, Co. Galway, Ireland.

3. Marine Scotland Science, Marine Laboratory, 375 Victoria Road, Aberdeen AB11 9DB.

4. Swedish University of Agricultural Sciences, Department of Aquatic Resources Institute of Marine Research, Lysekil, Sweden.

5. The Centre for Environment, Fisheries and Aquaculture Science, Pakefield Road, Lowestoft, Suffolk NR33 0HT, United Kingdom.

6. Technical University of Denmark, National Institute of Aquatic Resources,

Charlottenlund, Denmark.

7. Institute of Marine Research, Bergen.

8. Johann Heinrich von Thünen Insitute, Institute of Sea Fisheries, Hamburg, Germany.

9. Countryside and Community Research Institute, Oxstalls Lane, Longlevens,

Gloucester GL2 9HW.

10. European Commission, Joint Research Centre IPSC, Maritime Affairs Unit, TP 051, 21027, Ispra, Italy.

11. The Institute for Agricultural and Fisheries Research (ILVO), Ankerstraat 1, B-8400 Ostend, Belgium.

Corresponding author: Sarah B. M. Kraak, Marine Institute, Rinville, Oranmore, County Galway, Ireland. Email: sarah.kraak@ marine.ie. Phone +353 (0)91 387392. Fax +353 (0)91387201. 


\begin{abstract}
The performance of the EU long-term management plan for cod stocks, in force since 2009 , is analysed focusing on the human and institutional factors. The plan operates through landings quotas (TACs) and effort restrictions following a Harvest Control Rule, and deploys a novel instrument allowing Member States to 'buy back' or increase fishing effort for fleet segments engaged in cod-avoidance measures. The stipulated fishing mortality reductions have not been achieved. On the positive side, the 'buy-back' instrument has led to increased uptake of selective gear and implementation of permanent and real-time temporary closures. On the negative side, ignoring the dimension of fishers as reactive agents in the design, the impact assessment, and the annual implementation of the measures has contributed to the failure to adequately implement the plan and achieve its objectives. The main problem is that the landings quotas taken in a mixed fishery did not limit catches because fishers were incentivised to continue fishing and discard overquota catch while quota for other species was available. The effort limitations intended to reduce this effect were insufficient to adequately limit fishing mortality in targeted fisheries, although fishers experienced them as prohibiting the full uptake of other quotas. Recommendations for future plans include (i) management through catch rather than landings quotas, (ii) the internalisation of the costs of exceeding quotas, (iii) use of more selective gear types, (iv) the development of appropriate metrics as a basis for regulatory measures and for evaluations, (v) participatory governance, (vi) fisherybased management, (vii) flexibility in fishing strategy at vessel level.
\end{abstract}

Key words: cod recovery plan, fisher responses, Harvest Control Rule, mixed fisheries, results-based management, spatiotemporal measures 


\section{Introduction}

Worldwide, a large number of fish stocks are overexploited or depleted [1], and fisheries management has not always been successful in preventing or reversing these trends. However, several cases of successful management exist and fisheries scientists are analyzing the factors that may contribute to successful and unsuccessful fisheries management [2-6]. Fisheries management is evolving and drawing on the new insights, including in the context of management of depleted stocks where recovery is required.

A successful recovery plan should have well-defined objectives to be reached over finite time-scales [5], clearly defined biological reference points, and a set of unambiguous harvest control rules agreed by all stakeholders that will determine the appropriate level of fishing in each year [6]. The monitoring process should be transparent with simple and easily understood metrics [5]. Prior to implementation the plan should be evaluated to the extent possible, by simulation, to ensure its robustness to prevailing uncertainties [7-9]. There is growing awareness that resource users should be involved in decision-making if fisheries management is to be sustainable $[10,11]$. Successful plans often incorporate fishers into the science process in cooperative research activities [5].

Sometimes, however, the implementation of policies may have undesirable outcomes owing to the lack of a predictable relationship between the control measure used, e.g. landings or effort limits, and the outcome desired, e.g. a level of catch or fishing mortality [2]. Unsuccessful plans have often taken little precaution in the face of such implementation uncertainties [5]. One source of unexpected outcomes that has not yet received much attention in fisheries management occurs when fishers respond in unanticipated ways, even if their behaviour is perfectly rational and could in principle be predicted; not taking the fisher behaviour into account may undermine management and threaten sustainability [2]. These problems arise if the basic mismatch between individual incentives and desired system-level outcomes is not fully understood or addressed $[2,5]$. Among other problems, one of the most difficult seems to be the issue that within mixed fisheries the different stocks may differ in productivity and therefore need different levels of restriction of their removals $[5,12]$ and this may lead to 'implementation overfishing' [13] of the stock that is most in need of restriction. These mixed-fishery issues have been recognized as a problem in demersal-fisheries management by scientists, managers, and fishers [14], but in many cases have not yet been resolved. Murawski [5] concludes that the 'ugly' cases require creative and innovative solutions involving spatial management, "bycatch engineering", and in some cases balancing short- and long-term social and economic tradeoffs.

Since 1983 the European Commission (EC) has been managing the commercially exploited fish stocks in the European waters under the Common Fisheries Policy (CFP) [15], the main instruments of which are the annual Total Allowable Catches (TACs), supplemented by various technical measures, including closed areas/seasons, effort regulations and gear regulations. TACs were selected as the primary metric for control in order to allow annual stability in the national allocation of available resources, reducing 
the scope for international arguments but leading to difficulties owing to the "relative stability' implied by the agreement. Partly to avoid the annual political battles over setting the TAC, and partly as a result of knowledge drawn from successful fisheries management $[6,16]$, multi-annual or long-term management plans (MAMPs, LTMPs) are increasingly being implemented [17]. In EU waters, among other aspects, these MAMPs prescribe, usually through a Harvest Control Rule (HCR), how the annual TACs should be set and whether they should be accompanied by fishing effort restrictions or other technical measures.

Following serious depletion of four of Europe's cod stocks to well below the biomass limit reference points by the early 2000s, the EU agreed that stringent action was required to recover these and established a structured plan aimed at increasing stock biomass. The first cod recovery plan which aimed at recovering all four stocks with a common approach [Council Regulation (EC) No 423/2004] included requirements to reach biomass targets in a prescribed way and imposed a schedule of reductions in days at sea. In contrast with the current plan, where gear groupings are highly aggregated with only 8 gear groups defined relating only to mesh size bands and generic gear types, the previous cod plan regulated fishing effort across 39 different pseudo-metiérs including definitions based on a range of other technical attributes of the gear, e.g. square mesh panels, grids and a variety of catch (landings) composition limits. In some cases there were perverse incentives to decrease mesh size due to higher effort allocations

Traditionally in Europe, TAC and effort limitations of the type described above have been implemented as a broad-brush top-down management based on single-stock objectives, though for sole and plaice in the North Sea a joint plan has been implemented [Council Regulation (EC) No 676/2007]. However, it is becoming increasingly clear that these broad-brush regulations often lead to contradicting and perverse incentives, such as: the race to fish; the incentive to take up smaller rather than larger mesh sizes; and in mixed fisheries the incentive to go on fishing for species for which there still is quota available while legally discarding fish caught in excess of available quotas for other species $[12,18]$. These undesirable consequences of management policies not only undermine the fisheries management objectives directly [2] but also result in low stakeholder support which is important for higher levels of industry compliance to management regulations $[10,19-23]$. Thus, the EC is shifting away from its broad-brush, central and top-down management, towards governance on a more participatory and regional basis. The CFP reform in 2002 had already started a process of strengthened participation, and the EC is exploring further possibilities to increase participation in the decision-making process for future reform [24, 25]: it is envisaged that the general framework for fisheries policy would be set on the basis of a Commission proposal, but detailed implementing decisions, such as the types of gear or the areas and periods closed to fishing, could be taken at the regional or national level, and increased fishers involvement is encouraged.

Reflecting this shift and noting little improvement in cod stocks, a revised management plan for the exploitation of four European cod stocks [Council Regulation (EC) No $1342 / 2008$ - hereafter called 'the cod plan' or 'the plan'] was developed. The new plan is 
based on an HCR specifying target fishing mortality rate (implemented through rules for setting TACs supplemented with effort limits), but, significantly, adds a set of new management instruments that encourage the introduction of bottom-up, or at least nationally proposed and organized, approaches to minimise cod catches (Articles 11 and 13). These Articles provide incentives for cod avoidance in the form of an increase in allowable effort (Article 13) or total exclusion from effort restrictions (Article 11) if codcatch-avoidance measures are undertaken by a group of vessels. The way in which cod avoidance may be achieved is left open to the Member States and the industry, e.g. through the use of highly selective gear or implementing spatiotemporal modifications of fishing activity. As such, these articles are an innovative instrument following the new regional and fisheries-tailored 'results-based' management paradigm. 'Results-based' management has recently been described as: "instead of establishing rules about how to fish, the rules focus on the outcome and the more detailed implementation decisions would be left to the industry. Public authorities would set the limits within which the industry must operate, such as a maximum catch or maximum by-catch of young fish, and then give industry the authority to develop the best solutions economically and technically." [24].

Another recent development in EU fisheries management is the recognition that controlling the actual catches through 'catch quotas', i.e. landings plus discards, is in general a more appropriate management tool $[26,27]$ than the traditional TAC, which refers to the total allowable landings where discarding of overquota catches is legal. Following this new 'catch quota' paradigm, some elements in the cod plan, notably Articles 11 and 13, explicitly refer to catches (interpreted as landings plus discards, as explicitly stated in Article 11 and implied in Article 13). However, it is important to note that the control of catches requires different methods, such as inter alia on-board observation by observers or cameras [27].

This paper analyses progress so far on the road of improving fisheries management in the context of these new paradigms in setting fisheries policy. The cod plan is reviewed and compared against some 'lessons learnt' in the recent past to see which lessons have actually been taken on board and which have not. The paper considers new problems that arose when the new paradigms were gradually implemented and offers suggestions for further improvements. This paper focuses only on the human and institutional factors that may have influenced, positively or negatively, the outcome of the plan, but does not attempt to consider the biological factors influencing stock dynamics.

\section{The regulation}

The Regulation 1342/2008, establishing a long-term plan for cod stocks and fisheries exploiting those stocks, entered into force on the $1^{\text {st }}$ January 2009 . The Regulation establishes a plan for four cod stocks in the geographical areas of (i) Kattegat, (ii) the North Sea including the Skagerrak and the eastern Channel, (iii) the West of Scotland and (iv) the Irish Sea. Management for the North Sea cod stock is shared by the EU and Norway, and the HCR for this stock has been developed jointly by the EU and Norway. 
The plan includes an obligation for the Commission, on the basis of the advice from the EU Scientific and Technical Committee for Fisheries (STECF) and after consultation with the Regional Advisory Councils (RACs), to evaluate the impact of the management measures on the cod stock and the fisheries on those stocks in the third year of its application, and then each third successive year. The authors of this paper have been actively involved in the impact evaluation that was undertaken by a joint STECF-ICES expert group (hereafter called 'the group') between February and June 2011. Most of the material referred to in this paper has been produced specifically for that evaluation; for methods of analyses and other details the report produced [28] should be consulted.

\subsection{The objective}

The only stated objective in the regulation is [Article 5(1)] "to ensure sustainable exploitation of the cod stocks on the basis of maximum sustainable yield" through achieving fishing mortality rates (F) of 0.4 or below [Article 5(2) and Article 8(4)]. In practice, while fishing mortality rates are currently too high, this means the plan's objective is to reduce them toward or below $\mathrm{F}$ of 0.4 .

\subsection{The HCRs and the TACs}

The HCRs (except the one for the North Sea cod stock) specify that the ultimate target F is 0.4 unless the stock is below the minimum spawning biomass level $\left(\mathrm{B}_{\text {lim }}\right.$, as defined for each stock in the plan, Article 6), in which case $\mathrm{F}$ is to be reduced further by $25 \%$ per year. The annual reductions in $\mathrm{F}$ needed to reach the target are $10 \%, 15 \%$, and $25 \%$, in the respective cases that SSB is (i) at or above the precautionary biomass level $\left(\mathrm{B}_{\mathrm{pa}}\right.$, as defined for each stock in the plan, Article 6), (ii) below $\mathrm{B}_{\mathrm{pa}}$ but at or above $\mathrm{B}_{\text {lim }}$, or (iii) below $B_{\text {lim. }}$. An additional constraint that TACs shall never change more than $\pm 20 \%$ yearon-year has a higher priority than all other elements of the HCR (Article 7). The HCR for the North Sea stock is similar but differs in several details (e.g., different year-on-year reductions in $\mathrm{F}$, and partition into a recovery and long-term phase; Article 8). For all four stocks the TACs are to be set according to a short-term forecast based on the F specified by the HCR (Articles 7 and 8 ). The Regulation states that under poor data conditions, which do not allow for an analytical assessment and short-term forecast, the TAC shall be reduced by $25 \%$ or by $15 \%$ (the level depending on STECF advice) compared to the TAC set in the previous year (Article 9).

\subsection{The effort regime, Article 12}

In Article 12 the Regulation stipulates, for each of the four management areas, a maximum allowable fishing effort (in $\mathrm{kW}$-days) for each of a series of gear groups of EU vessels. Effort adjustments are applied annually to those groups which are together responsible for more than $80 \%$ of the EU cod catches in each of the management areas. Annual reductions of effort will be by the same percentage as specified for F in the HCR (or as specified for the TAC under the data-poor condition). There are two provisions within the plan that allow (i) for an increase in fishing effort relative to the annual allocation (Article 13) and (ii) for the exclusion from the effort regime entirely (Article $11)$. 


\subsection{Article 11, excluding groups of vessels from the effort regime based on low cod catches}

Article 11 allows Member States to request that groups of vessels are excluded from the effort regime if the cod catches do not exceed $1.5 \%$ of the total catches of all species (landings plus discards) by the group of vessels concerned. The regulation does not specify how the $1.5 \%$ catch should be achieved, focussing on the outcome rather than the technical means to achieve it.

\subsection{Article 13, allocating additional effort for highly selective gear and cod-avoiding trips}

Article 13 provisions allow for the reclaiming of effort in the following ways:

13.2. The maximum allowable fishing effort may be increased within effort groups in which the fishing activity of one or more vessels:

(a) is carried out having on board only one regulated gear the technical attributes of which result, according to a scientific study evaluated by STECF, in catching less than $1 \%$ cod (highly selective gear);

(b) results in a catch composition of less than $5 \%$ cod per fishing trip (cod-avoiding fishing trips);

(c) is conducted in accordance with a cod avoidance or discard reduction plan which reduces

fishing mortality for cod among participating vessels by at least as much as the effort adjustment referred to in Article 12(4); or

(d) is carried out in the west of Scotland area to the west of a line [approximating the $200 \mathrm{~m}$ depth contour] provided that the participating vessels are equipped with satellite-based vessel monitoring systems (VMS).

\section{Did the plan achieve its objective?}

\section{$3.1 \mathrm{~F}$ targets and stock recovery}

The group [28] concluded that the objectives have not been met as $\mathrm{F}$ has not been reduced to the levels envisaged by the plan; no reductions in $\mathrm{F}$ are observed for the Irish Sea and West of Scotland stocks, and an average annual reduction in F of $1.5 \%$ for the North Sea is observed for 2009 - 2010. For cod in the Kattegat recent trends in F cannot be reliably estimated from the assessment; however some reduction in fishing impact has likely taken place. While mortality on the stocks is considered to be well above the levels intended by the plan, the exact level of $\mathrm{F}$ is unknown due to uncertainties arising from inter alia unallocated removals (see section 5.1.1), catches in excess of TAC, and other sources of mortality. Medium term simulations [28] based on the current rate of change per year in F suggest that for the North Sea, the Irish Sea and the West of Scotland stocks it is highly unlikely that, following the current implementation approach, $F$ will reach $F_{m s y}$ by 2015 . For Kattegat cod it was not possible to evaluate the likely success in terms of $\mathrm{F}$ reductions by 2015. In contrast, for Eastern Baltic cod the required reductions in $\mathrm{F}$ have been achieved but under a number of different conditions: this stock is fished in a single-species fishery; stronger year classes have occurred; reductions in fishing effort 
resulted from a substantial tie-up of Polish vessels; and enforcement was improved [29]. Although estimated SSB in 2011 for North Sea and West of Scotland cod has increased to almost twice the lowest observed SSB (in 2006), the SSBs of all four cod stocks are currently likely to have remained below $\mathrm{B}_{\lim }[30,31]$.

\section{Did the plan result in changes conducive to the aims of the plan?}

In this section it is examined whether or not the plan resulted in any changes that may have helped in the direction towards achieving the aim of the plan. In the next section (section 5) factors are explored that may have contributed to the non-achievement of the plan.

\subsection{TAC setting}

Analytical assessments with short term forecasts were accepted only for the North Sea cod stock; the agreed TACs were set in accordance with advice based on the plan's HCR since its implementation in 2009 (Article 8). The cod stocks in the Kattegat, the Irish Sea, and the West of Scotland were classified as data-poor due to the lack of short-term forecasts, and thus the plan stipulated that their TACs should be set as a percentage of the previous year's TAC (Article 9). For the Irish Sea stock the agreed TACs have indeed been set in accordance with the plan since its implementation. For the Kattegat the TACs were also set in line with the plan for the first years but the reduction in 2011 was greater than specified under the plan. For the West of Scotland cod, in 2009 the TAC was set lower than stipulated, in 2010 higher than stipulated, and in 2011 approximately in line with the plan. In conclusion, the plan has been successful in setting the TACs in accordance with its stipulations.

\subsection{Catches}

Overall catches (estimated landings and discards) through time show different trends in the different areas (Figure 1), as do patterns of discarding. In the Irish Sea stable catches between 2003 and 2008 have been followed by two years of lower values. The estimated trawl discard rates are very erratic and there is uncertainty about their reliability. In the Kattegat, landings have declined to less than one tenth of the amount reported in 2003. Discard rates are highly uncertain but currently estimated at around 30-50\% of total cod catch with no obvious trend. North Sea catches increased after 2006, reflecting the contribution of the relatively larger 2005 year class and associated increases in TAC. Discard rates by trawlers with mesh $>100 \mathrm{~mm}$ in the North Sea were also influenced by the 2005 year class and rose to $53 \%$ in 2008 followed by a decline to $20 \%$ in 2010 . West of Scotland catches have fluctuated without any trend between 2003 and 2010 and remain high despite progressive reductions in TAC. The predominant cod catching gear there is trawl with mesh $>100 \mathrm{~mm}$ and the discard rate for this gear has risen steadily. In the last two years known catches were 6 to 7 times higher than the TAC.

\subsection{Effort reductions, Article 12}

There were marked reductions in overall effort in all areas before the cod plan came into force, as a result of large decommissioning schemes and the previous cod plan, but these 
trends levelled off during the first years of the current plan [32] (Figure 1). In all areas, regulated effort declined as stipulated by Article 12 of the plan, but it did not decline in line with the stipulated F reductions, owing to an elevated baseline (see section 5.2.1) and application of Articles 11 and 13.

\subsection{Article 11, excluding groups of vessels from the effort regime based on low cod catches}

Since the current plan's implementation, several groups of vessels have been exempted from the effort restrictions. Some of these achieved the low cod catches through the use of selective gear such as a separator grid ('technical decoupling'), and others through limiting their operations to waters deeper than 200-300 m, which is outside the normal distribution of cod ('spatial decoupling'). However, for some exempted groups of vessels, e.g. those targeting saithe or Nephrops, it seems more likely that very low cod catches are achieved because the cod stock is severely depleted in the areas of the fishing operations (see section 5.3).

Whether it was intended as such or not, Article 11 encouraged fishers to use selective gear or fish outside the distribution area of cod or in other ways avoid cod catches. More vessels have chosen to use the selective gear (particularly in Sweden) or to fish in the deeper waters, as evidenced by the increase in effort by exempted vessels from 2009 to 2010 [Annex 7 in 28] (Figure 1). Thus, this Article could have contributed positively towards achieving the aims of the plan.

\subsection{Article 13, allocating additional effort for highly selective gear and cod-avoiding trips \\ In 2009 and 2010 a number of Member States have used extra effort under Article 13, through adopting gear modifications or spatiotemporal measures. Ireland, the UK, Sweden and Denmark have all introduced spatial and temporal closures to reduce cod catches (Figure 2).}

All Danish and Swedish vessels fishing in Kattegat are subject to the joint Danish and Swedish seasonal and/or permanent area closures in Kattegat and the Northern part of the Sound, implemented from January 2009. In a large part of the closed area, only a fishery with selective gears is allowed, which has created incentives for the industry to use selective gears. In the first year of implementation of closures, fishing effort in Kattegat was moved from high cod density areas to areas with lower cod density. However, already in the following year, a large part of the effort was concentrated in the closed area, where cod density is in fact highest, but where a fishery (targeting mainly Nephrops) with selective gears is allowed [28].

The Scottish Conservation Credits Scheme (CCS) is a co-management initiative involving industry, NGOs, scientists and government officials, that rewards the adoption of cod avoidance behaviours and reduced cod catch rates by returning to fishermen some of their deducted effort. The scheme has a compulsory element requiring all vessels to avoid Real Time Closures (RTCs) [33, 34] and an optional component comprising a schedule of alternative selective gears which attract varying degrees of effort buy-back 
depending on the estimated reduction in cod catch. The level of implementation of the spatial measures has been quite high and compliance by Scottish fishermen is reported to have been good. Similar RTC schemes applied to all vessels have been introduced in other parts of the UK to reduce F on cod. Closed areas are identified based on reports of high cod abundance by fishers, through sampling by fisheries-enforcement vessels, or on the basis of landings per unit of effort (lpue).

Despite extensive and ongoing research into the development of fishing gears that reduce the capture of cod, the uptake of these has been less successful across métiers and areas in comparison to adherence with spatial closures. Uptake of species selective gears that reduce cod catches in whitefish fisheries have been limited (North Sea) or absent (West of Scotland). Uptake of selective gears has been better in Nephrops fisheries in general, with widespread use of gears in the Kattegat and some uptake in the Irish Sea. The lower levels of uptake are probably due to losses of other target species when trying to exclude cod.

It is extremely difficult to evaluate whether the changes in fishing behaviour resulting solely from Article 13 have led to reductions in fishing mortality [28, 35]. However, a reduction in fishing impact (proxy for fishing mortality) in the Kattegat has likely taken place, resulting from a combination of measures (closed areas plus gear regulations) covered by Articles 11 and 13 [28]. Similarly, the combination of measures implemented in the North Sea through the Scottish CCS in 2009 were considered to have contributed to partial $\mathrm{F}$ values that were lower relative to the total $\mathrm{F}$ than before implementation [35]. In 2010, Scottish North Sea catches were in line with those predicted by ICES forecasts and there was a further reduction in Scottish discards, but the estimated reduction in catches through the CCS RTCs was only about half that anticipated. The CCS applied to the West of Scotland stock was not considered to have reduced cod catches significantly [36].

\subsection{Spatial effort distribution}

It might have been expected that fishers faced with limited TACs would have modified their fishing activities to avoid areas with high cod abundance while targeting other species. This may have happened in the North Sea (see section 4.7); however, an analysis of the spatial effort distribution of the main Irish fleets operating in the Irish Sea and West of Scotland based on 2006-2010 VMS data suggested that, contrary to the intended effect of the plan, the effort deployed in areas with (temporally) medium and high cod abundance steadily increased [Annex 9 in 28].

\subsection{Fishers' perspectives}

As part of the current evaluation of the plan, the EC had financed a sociological study, commissioned by the RACs, using a survey among 14 vessel owners and operators in the North Sea [Annex 17 in 28]. Fishers in the North Sea reported that they have tried to avoid areas with high density of cod and even left areas when it was clear that they were catching too much cod, even if they were targeting other species in these areas. This behaviour is in accordance with the intentions of the plan. On the other hand, some 
fishers found that cod TACs were not sufficient, and reported discarding fish above minimum landing size, indicating that cod avoidance, if occurring, may not be sufficient.

\section{Why did the plan not achieve its objectives, and could it have been known in advance?}

In this section it is discussed what the group identified as possible causes for the plan's current failure to achieve its objectives. Moreover, it is discussed to what extent this could have been known in advance; in other words: To what extent were lessons learnt in the past ignored?

\section{1. TACs}

\subsubsection{Discards and unallocated removals are not constrained by TACs}

For all four stocks there have been substantial discards indicating that the TAC was unable to restrict total removals from the stock (Figure 3). In 2009 and 2010 known catches from the West of Scotland stock were as much as 6 to 7 times the TAC. In addition, estimated unallocated removals (unknown mortality) are also high for all four stocks, and it remains unclear to what extent the unallocated removals are caused by the fisheries (either through black landing or by discarding beyond what can be monitored by onboard observers) or biological causes (e.g. migration, additional natural mortality). In the case of the West of Scotland stock, an assessment model fitted to landings and discards data, survey indices, and estimates of cod consumed-at-age by grey seals in two years [37] suggests that predation mortality on cod is greater than previously thought, increased with the seal population from the mid 1980s into the mid 1990s, and was not accommodated for sufficiently in the treatment of natural mortality in previous assessments. Seal predation on cod is primarily on ages 1 to 3 with the greatest predation mortality at age 3 , at which age it is equivalent to that from fishing. The seal population in the area is believed to have been stable since the mid 1990s but the best fit to the available data came from a feeding model allowing per-seal predation mortality to increase with decreasing cod biomass, suggesting a preference for cod in the seal diet rather than consumption simply being a function of encounter rate. Therefore, even with a stable seal population, the mortality rate seals impose on cod can continue to rise. The high discard rates and non-fishery removals are a serious concern preventing the plan from being successful in achieving its objectives. This is confirmed by the example from the Baltic Sea, where recent better control over removals played a major role in achieving a reduction in fishing mortality on the eastern Baltic cod down to the level corresponding to the target of the management plan implemented for the Baltic cod stocks [29].

\subsubsection{The intermediate-year assumption as stipulated in the plan is violated}

For the North Sea stock the setting of the TAC followed the management plan HCR, using inputs from the stock assessment and a short-term forecast (Article 8). As prescribed in the regulation (Article 7(4); for Article 8 the equivalent prescription has been assumed), the short-term forecast was based on the assumption that in the intermediate year $\mathrm{F}$ would have been reduced in line with the stipulations from the HCR. 
However, this assumption was analysed and found to be inappropriate; it resulted in an under-estimate of the intermediate year fishing mortality compared to that which subsequently resulted [28]. The effect of this would be that the F in the TAC year was higher than intended by the plan, and this is likely to have contributed (with the increased discarding mortality) to the inability of achieving the objectives of the plan. It should be noted that, although ICES based the forecast that was used for final advice on the assumption that in the intermediate year $\mathrm{F}$ would have been reduced in line with the $\mathrm{HCR}$, it advised that the stipulated intermediate-year assumption was unlikely to be achieved as fishing mortality reductions had not been realised, and included an alternative assumption that there was no decrease in $\mathrm{F}$ in the intermediate year [38, 39]. One likely explanation why managers may have ignored the limitations of the advice was the pressure from the fishing industry to increase TACs arguing that this would reduce discards of overquota cod. Indeed, it is speculative whether lower TACs would have really improved the situation or would have just led to more discards given the general bycatch problem in the mixed demersal fishery (discussed in section 5.1.3.).

Where agreed management plans are available and found by ICES to be consistent with the precautionary approach (but see section 5.5), ICES will provide advice according to the management plan, and will place this advice (usually including a single number representing the TAC) in a prominent position in the advisory text (e.g. see p99, "single stock exploitation boundary" in [40]). Although ICES always addresses the uncertainty related to data, the assessment, and the short term forecast in working group reports and advice, these uncertainties do not usually receive the same prominence in the advice text as the TAC. Kraak et al. [41] view the requirement of simple answers by the management system (i.e. calculating a TAC according to a specified management plan HCR) as potentially conflicting with the need for scientific rigour (i.e. pointing out uncertainty and the invalidity of the assumptions when they arise), and argued against the mechanisation of scientific advice (e.g. by HCRs that are applied without circumspection). Furthermore, they propose that fisheries advice should be a dynamic process of expert judgement. Such a process does to a certain extent take place in the ICES Advice Drafting Groups, but these groups would usually support the outcome of a management plan, if one as described above exists.

The application of HCRs without circumspection (here in the context of evaluating the ability of HCRs to achieve pre-specified objectives in the face of uncertainty) was one of the main reasons why the International Whaling Commission moved away from the "New Management Procedure" to develop the "Revised Management Procedure" (RMP) in the mid to late-1980s through the pioneering work of de la Mare [7, 42]. The simulation framework that underpinned the RMP is currently applied to fish stocks world-wide in the form of the "MP Approach" (sometimes also called "Management Strategy Evaluation", "MSE" [16]) [8]. Although the end-product of the MP Approach is a management procedure (including HCR) that is run on "auto-pilot" for a period of time (typically 3-5 years), it is not without circumspection, because such circumspection has gone into the design of the MP Approach framework, and because further circumspection is provided through provisions to switch off the "auto-pilot" and re-evaluate the 
management procedure if assumptions that underlie the MP Approach are violated (e.g. the data stray outside the boundaries tested for [7, 43]).

Unfortunately, in the case of the cod plan, the HCR finally adopted had been put into force prior to testing by simulation and a formal MP Approach (sensu Rademeyer et al. [16]) was not followed (see section 5.5). Furthermore, the evaluation that was conducted did not account for the possibility that the intermediate-year assumption of achievement of the fishing mortality reductions would be violated. Moreover, no provision had been included in the plan that allowed switching off the "auto-pilot" when it was found that the intermediate-year assumption was not achieved. Apparently there is no process in place that could prevent applying the HCR based on a violated assumption, and the finding that reductions in $\mathrm{F}$ had actually not realised in the intermediate year therefore did not have consequences.

\subsubsection{Mixed fisheries}

One of the reasons for discarding (and the non-achievement of $F$ reductions) may be given by a 'lesson learnt' long ago but not yet heeded: the mixed-fisheries problem [12]. Implicitly, a single species TAC assumes that the fishing activity will adapt to the quota available for a particular stock, and will lead to the targeted level of fishing mortality. The simplest link is to assume that vessels will stop catching a given species once their quota for that species is exhausted. The likelihood that this assumption holds true declines for complex, multispecies, multi-gear fisheries where fleets are given a set of different fishing opportunities for the various stocks. The recent history of the North Sea cod is a good example of the problems of using TACs (as landings quotas) to manage mixed fisheries. In 2005-2006, the North Sea cod stock was at a historic low biomass whereas the stock of haddock, which is to a large extent caught together with cod, was at its highest biomass in 30 years [38]. A study on the mixed roundfish fisheries in the North Sea [18] made explicit that single-stock management objectives for cod and haddock cannot be achieved simultaneously using stock-based annual TACs because of conflicting incentives to the fleets. When the quota for cod was exhausted fishermen were faced with a dilemma: stop fishing and underutilize the quota for haddock, or continue fishing and discard or illegally land overquota catches of cod. If they chose the latter options, clearly the cod TAC would not achieve its intended conservation objective. Ulrich et al. [12] have developed a tool, Fcube, which is currently used in the ICES Working Group on mixed-fisheries advice for the North Sea [44, 45]. Fcube forecasts the likely catches of the various species in the mixed assemblage under a variety of management scenarios and assumptions about fishers' behaviour in relation to set quotas.

Fcube can thus forecast to what extent fishing opportunities for the other stocks in the assemblage will remain underutilized if all fleets would adjust their activity so as not to exceed their portion of the cod TAC; this is a measure of the friction experienced by the fishers trying to fully exploit all their fishing opportunities (Figure 4). The chosen mechanism deployed within the plan to attempt to restrict fishing activity in line with the fishing opportunities for cod, namely the stipulated effort restrictions, must have caused such friction (even though it did not prevent overquota catches of cod, see section 5.2) (Figure 4). Such friction is indeed reported by fishers, through the stakeholder reports 
[Annnexes 2 and 3 in 28] as well as the sociological survey [Annex 17 in 28]. Unfortunately, mixed fisheries advice is not yet incorporated in the final TAC advice, nor used by managers.

In conclusion, scientists and managers could have known that it is unreasonable to rely on TACs, implemented as landings quotas, based on single-species considerations, for the reduction of $\mathrm{F}$. Not having heeded this learnt lesson has quite likely contributed to the failure to achieve the plan's aim. If, for example, landings quotas were to be based on mixed-fisheries considerations, a set of landings quotas consistent across the various stocks could be agreed, representing a management-imposed compromise between overexploiting some and underexploiting other stocks. Then, provided that fisher behaviour had been correctly anticipated, overquota catches would be minimal and the landings would more closely resemble the agreed intended catches. Alternatively, if TACs were to be implemented as catch quotas (landings plus discards) rather than as landings quotas, and overquota catches forbidden, then the fishery would have to stop fishing when the first quota was exhausted. This would force fishers to change their behaviour and may lead to strong improvement in the ability to target species. For example, in the Canadian British Columbia trawl fishery, where individual transferable quotas govern TACs for 22 species, $100 \%$ observer coverage combined with the deduction of discard mortality from quotas, incentivised and enabled fishermen to adjust the species mixture in their catches [46]. In this instance the species compositions turned out not to be fixed, and bycatch of overquota species was not unavoidable.

The important conclusion for the future plans is that, in developing measures, it is important to include the likely responses by the fishery, not just to consider the headline targets from an HCR. This could be done in several ways: factoring in the responses; changing the regulatory approach to one that would function better; include likely levels of compliance in the study; and provide a technical annex to the regulation to modify the calculations if the indications are that the desired results are not being achieved (i.e. a possibility to switch off the "auto-pilot"). In this context, it would be useful to follow a full MP Approach including the dimension of fisher behaviour [2].

\subsection{Effort}

\subsubsection{Effort baselines were too high}

Baselines for Member States' allocations of effort (Kw·days) were related to a recent reference period (either 2004-2006 or 2005-2007, the choice of period being up to each Member State) irrespective of whether and when Member States had undertaken capacity reduction through decommissioning schemes or other means. This has meant that effort control has been experienced very differently by Member States depending on whether decommissioning and other measures took place during the reference period or earlier. Furthermore, in most cases the effort deployed in 2008 was already lower than the starting baseline (i.e. the effort in the reference period). Because the subsequent effort reductions were relative to the starting baseline while the $\mathrm{F}$ reductions were relative to the F in 2008, the allowed effort in 2009 could be higher than the 2008 effort or at least reduced to a lesser extent than the stipulated F reduction relative to 2008 (and similarly 
for effort and $\mathrm{F}$ in 2010 relative to 2009). This resulted in regulated effort reductions being smaller than specified $F$ reductions. Indeed, in some cases effort has not yet been restrictive, even after the successive reductions of allowed effort since 2008. This may have contributed to the failure to achieve the plan's aim.

\subsubsection{Effort reductions do not necessarily result in proportional $F$ reductions}

Article 12 stipulates effort reductions by the same percentages as the reductions in $\mathrm{F}$ (according to the HCR, Articles 7 or 8) or TAC (Article 9). This does not imply that the regulation assumes a proportional relationship between $\mathrm{F}$ and effort. The regulation simply stipulates that effort reductions are continued until $\mathrm{F}$ is reduced to the required target value. Indeed there are many reasons why the proportionality between $\mathrm{F}$ and effort may not occur [47-51]. Factors influencing the partial F exerted per unit effort (Fpue) by a vessel, include skipper skills, auxiliary equipment, gear, the area and the season of the fishing operation, costs, revenues, and other incentives leading to business decisions such as targeting or avoidance. This implies that, depending on the predictability of catchability by fishers, management-imposed reductions in effort might not translate directly into a proportional reduction in F. Fishers faced with such effort reductions can allocate their remaining effort such that they maximise catches of their targeted species to minimise the impact on revenue. Another effect is that the spatial distribution of a stock may contract with declining population biomass but without affecting the fish densities in the core habitat of the species [52]. Thus, if fishers faced with effort reductions contract their activity to these core habitats, fishing mortality may remain high despite the reduced effort. According to the sociological survey [Annex 17 in 28], the plan indeed had the effect that fishers had behaved more efficiently in order to maximise revenues from fishing trips. The economic analysis of the group [28] (regarding a subset of fleet segments operating in the North Sea only) found that overall revenues-per-unit-effort increased while costs-per-unit-effort decreased over the period 2006-2009. Aggregate fishing profitability increased over the period, but the importance of cod in total fishing revenues declined. Fleet capacity was reduced, but consolidation has been in favour of larger, more powerful and more efficient vessels (following the general predictions of $[47,51])$. Clearly these changes in fisher behaviour and fleet structure would not likely result in a decline of cod $\mathrm{F}$ proportional to the decrease in effort.

As an illustration of the potential of revenue-maximising behaviour, logbook data from Irish demersal trawl trips in 2010 indicate that if the $25 \%$ least efficient trips (those with the lowest revenue per unit effort) are omitted from the dataset, the cod catches are only diminished by $5 \%$ and $7 \%$ respectively for the directed cod fisheries (in the Irish Sea and West of Scotland with mesh size $>99 \mathrm{~mm}$ ), and by $23 \%$ in a bycatch fishery (in the Irish Sea with mesh size 70-99 mm) [Annex 6 in 28]. This also suggests that the relationship between effort and $\mathrm{F}$ in target and bycatch fisheries may be different: the relationship between effort and F may be much more linear for a situation where cod is caught in a bycatch fishery. This is also shown for North Sea cod over the period 2003-2009 [Figure 5.1 and Annex 12 in 28], where the trends in F are better correlated to the trends in effort of gears catching cod as a bycatch (Nephrops trawl with mesh 70-99 $\mathrm{mm}$ and flatfish beam trawls) than in cod-targeting trawls with mesh $\geq 100 \mathrm{~mm}$. Thus, effort limitations may be effective in controlling bycatch but have less impact on controlling $\mathrm{F}$ in target 
fisheries as these fishers can modify their behaviour to mitigate the effort regulation. Nevertheless, this interesting notion needs further study to be corroborated.

\subsection{Article 11, excluding groups of vessels from the effort regime based on low cod catches}

STECF [53] has pointed out that the current low cod stock is likely to result in catches of cod of particular groups of vessels being $<1.5 \%$ of total catch, allowing them to qualify for effort exemptions. These vessels could potentially negate any attempts to reduce cod mortality and could inhibit re-colonisation of depleted areas and in turn stock rebuilding.

The use of bycatch limits as specified in Article 11 (and Article 13, see section 5.4) is a potential flaw in the design of the plan. There is no a priori clear relation between the percentage of cod in the catch and the fishing mortality rate on cod: (i) a low cod percentage may be achieved when abundance of cod is low but in such a case it would represent a high F; (ii) a lower cod percentage may also be achieved by increasing the catches of other species (while keeping cod catches at similar levels) and a perverse incentive may arise in favour of using smaller mesh gears to achieve a higher overall catch; (iii) catch compositions also depend on the relative abundances of the various other stocks in the mixed catch assemblage so that a small cod percentage may simply be indicative of higher abundances of other stocks; (iv) if many vessels have a small percentage of cod in their catch, the total amount of cod caught may still be high. The latter also applies if very many vessels are exempted on the basis of their use of selective gear, since these gears always continue to catch some cod.

Despite the identification of bycatch limits as potentially flawed, it does not seem that the use of Article 11 has greatly contributed to the failure of the plan to achieve the stated objectives, since very few exemptions have been granted under this Article and the catches of cod by vessels exempted from the effort regime under Article 11 represented only a small proportion of the overall cod catches made by regulated gears (5\% or less) (Figure 1).

\subsection{Article 13, allocating additional effort for highly selective gear and cod-avoiding trips}

The verification aspects of Article 13 are too complex [28, 35], especially for areas where there is no analytical assessment. It is difficult to disentangle the effects of specific and multiple measures on F, particularly when the entire fleet participates in the programme (as in the Scottish case) because there is no possibility to compare against vessels that are not participating. Despite the difficulties in formal evaluation, observations point to positive effects and reduced catches of cod in some areas operating under Article 13 although the effect is not apparent everywhere (e.g. not on the West of Scotland stock). Overall, the allocation of additional effort under Article 13 has in the majority of cases not been demonstrably accompanied by the required reduction in F on cod owing to the avoidance measures implemented. This may have contributed to the failure of achieving the plan's objectives. 
Since the provisions of Article 13(a) and (b) are based on catch composition limits expressed as percentages of cod in the catch, these article members suffer from the same design flaw as was discussed above (section 5.3).

\subsection{Impact assessments}

In 2008-2009, impact assessments of the plans were carried out by ICES; all these impact assessments, except for North Sea cod, were conducted after the plans were already in force $[54,55]$. Even in the case of the North Sea cod plan, what was evaluated prior to implementation was proposals from the EC and Norway [54], and not the plan that was eventually implemented (which was only evaluated after implementation) [38]. Various scenarios were tested, but in its final advice for the North Sea plan ICES [56] had assumed that the annual effort reduction and the intended $\mathrm{F}$ would be fully achieved. ICES [56] considered the North Sea cod plan to be "in accordance with the precautionary approach if it is implemented and enforced adequately" [our italics] and stated that "discarding in excess of the assumptions [our italics] under the management plan will affect the effectiveness of the plan", and noted that "the evaluation is most sensitive to assumptions about implementation error [our italics] (i.e. TAC and effort overshoot and the consequent increase in discards) and a continuation of the current low recruitment.".

It would have been helpful if the Terms of Reference of the request for advice from ICES in its impact assessment had included a request for an exploration of the likelihood of adequate implementation and enforcement [2]. It could have been predicted that fisher response under the proposed regulations might give rise to increased discarding (e.g. owing to the mixed nature of the fisheries), and ICES could thus have advised on the more likely medium-term projection. In this case, the managers adopted the plan without advice on the likely fishery responses even though it was stated that its effectiveness would be very sensitive to the likelihood of adequate implementation, and no mechanism to switch off the "auto-pilot" was incorporated into the plan. It should be reiterated that it would be useful to follow the full MP Approach (e.g. as described in [16] including the consideration of fisher behaviour [2]) in the mixed-fishery context, and if possible including likely implementation issues related to responses to provisions such as Articles 11 and 13 .

\subsection{Stakeholder views}

In 2007 two stakeholder groups [the North Sea RAC (NSRAC) and the North Western Waters RAC (NWWRAC)] jointly organised a Cod Recovery Symposium held in Edinburgh [57]. The symposium reviewed the previous cod recovery plan [Council Regulation (EC) No 423/2004]. In the course of 2008 the EC and Norway published separate proposals for a new cod plan [58], resulting (after combining elements of the two proposals and implementing further modifications) in the plan currently in place. The RACs responded to the proposal with a number of opinion documents before the current plan came into force [59-62]. In the 2011 review process [28], the stakeholders were invited as observers to the scientific meetings and to submit their views in written documents. Two opinion documents, one of each RAC, were provided [Annexes 2 and 3 respectively in 28]. These opinion documents indicate that the cod plan is not fully supported by the stakeholders, in this specific case the fishing (capture) section of the 
industry. The NSRAC states that consultation before the plan was introduced had been inadequate.

In their opinion documents the RACs addressed a number of concerns relating to the design, development and implementation phases. They identified some perceived deficiencies and omissions in the plan, a lack of consultation during its development and a number of difficulties experienced in its implementation. Many of the concerns related to the effort allocation procedures which were felt to be based on overly rigid gear groupings that did not sufficiently account for the polyvalent nature of some fleet components and restricted the re-direction of effort to other fisheries. Concerns regarding the assumed link between fishing effort and fishing mortality were specifically highlighted. It was noted that economic issues were not considered during the development of the plan and that the percentage reductions in TAC and effort appeared to have been set at arbitrary levels, especially for the data-poor case. For the NSRAC it was of major concern that the plan continued to manage the fishery through landings limits and not through restrictions on total catch. This has in some cases led to conflicts with existing catch composition regulations and given rise to so-called regulatory discarding. The RACs commented that it has proved extraordinarily difficult to gain exemptions under Article 11 for vessels that do not catch cod. In particular, they experienced a lack of transparency over the criteria used to deliver exemption and over the data to be collected. Another issue highlighted by the RACs was that, in terms of implementation of the plan, there have been different approaches by different Member States and that the plan has not been easy to implement; it has shifted responsibility from the Commission to Member States, and has placed a very heavy burden on administrators and the fishing industry.

Both RACs support the notion of reducing cod F to sustainable levels and the necessity of taking up cod avoidance measures, but encounter a multitude of problems for the industry to do so. The RACs advocate effective cod avoidance measures on a fishery-by-fishery basis, to be obtained with the full involvement and cooperation of the fishers through selective gear, spatial and temporal avoidance, fully documented fisheries, and discard reduction strategies; the adaptive nature of the implementing rules and a results-based management would be the foundations for the success of any future cod management plan. Already at the Edinburgh symposium the RACs had emphasised the need for incentives to achieve cod avoidance. Both RACs appreciate the 'spirit' of the Article 13 provision but found it in practice non-transparent and difficult to implement.

The sociological survey [Annex 17 in 28] revealed that 8 out of the 14 respondents thought that other species were adversely affected by the plan through increased discarding or targeting, and 12 respondents indicated they had discarded fish, cod and other species, as a result of the plan (for example by high grading). However, it is unclear by what mechanism the cod plan encouraged the discarding of other species.

Respondents favoured more flexible rules that are more locally adaptable, or even down to the level of each vessel, for example allowing them to switch gear, in order to reflect the natural variability of the resource. Some would favour vessel-specific quotas (already 
available in some Member States), so that the fishers are able to decide when to fish based on their own economic considerations.

Apparently the cod plan was not supported by the stakeholders, and this may have contributed to the failure to achieve the plan's aims. In order for a plan to be successful, the problems mentioned by the RACs must be taken into account, not only because stakeholder support is important for compliance [19-23], but also because some of these problems have actually made adequate implementation of the plan much more difficult.

\subsection{Economic consequences}

In a critical paper on the previous cod plan, Kelly et al. [63] had commented that the plan had not considered the fishers' loss of revenue caused by reduced opportunities to fish (including other species), and recommended that future plans should consider these more explicitly. Unfortunately, the current cod plan did not do so, and this may have contributed to the failure to achieve the plan's aims. While it is not clear to the present authors in what form these should be considered, it seems a truism that ignoring them will not help to the success of a management plan. Murawski [5] also warned that sometimes the economic benefits in the fishing industry are substantially reallocated in the course of a plan's life, but that these economic consequences are often not anticipated or at least not explicitly communicated, exacerbating the gulf between managers and fishers. Failure to make explicit society's choices about how to restructure the fisheries to become sustainable may undermine the credibility of recovery programmes.

\section{Conclusions}

Some aspects of the plan worked towards reaching the objectives. Regulated fishing effort was reduced and/or is deployed under cod-avoidance conditions. Notably, through Article 13, the uptake of selective gear has started to increase in some areas, as well as the implementation of spatiotemporal measures such as permanent and real-time temporary closures. Stakeholders were in principle positive about Article 13, presumably because this allows fishers to avoid cod in a flexible way while trying to minimise the impact on other fishing opportunities. The uptake of selective gear and fishing at depths outside the distribution area of cod were also increased through Article 11, although this is variable across all areas; the maximum uptake has been seen in the Kattegat Nephrops fishery, with either moderate or minimal uptake in other areas. In general, some fishers report that they avoided cod, although cod avoidance outside the provisions of Articles 11 and 13 was not corroborated scientifically.

Factors contributing to the failure to achieve the plan's objectives can be summarized as follows:

- Although the TACs were set according to the plan's stipulations, in the case of the North Sea the TAC setting was based on assumed intermediate-year reductions in mortality that were not achieved in reality - which was known. Nevertheless, the increases in TAC resulting from this were likely small and it is not clear whether lower TACs would have resulted in better performance of the plan. 
- In a mixed-fishery context, relying on TACs implemented as landings quotas that are based on single-species considerations to control $\mathrm{F}$ is a flawed concept. A well-known cause for overquota discards in mixed demersal fisheries is the discrepancy between fishing opportunities for the different species and the tension this causes for fishers responding to economic considerations. Ignoring this amounts to ignoring the dimension of the fishers as rationally behaving agents.

- The effort restrictions were not effective, because the reductions started from baselines which for some member States were above the actual effort levels exerted in the year prior to the first year of the plan; consequently the realised reductions were less than the stipulated reductions in F. Moreover, it was known that broad-brush proportionality between effort and $\mathrm{F}$ is often invalid, especially in the case of a directed fishery, and the actual relationship is likely to be complex, non-linear, and probably fishery-dependent. This is another behavioural dimension that was ignored.

- The allocation of additional effort under Article 13 has in the majority of cases not been demonstrably accompanied by the required reduction in F on cod owing to the avoidance measures implemented.

- Although the impact assessments had warned that the success of the plan was sensitive to implementation error, the problems of implementation related to the likely fishery responses to the plan were not explored.

- The stakeholders, in this case the fishing (capture) section of the industry, did not fully support the plan; in particular, they did not support TACs implemented as landings quotas and they did not support effort reductions. Lack of stakeholder support not only diminishes compliance, but may also reflect the inability to adequately implement the plan. Problems experienced by the stakeholders were: contradictory requirements, lack of flexibility, and definitions of vessel groupings that were too broad.

From this list it appears that a major reason for the failure to achieve the plan's aims has been that fisher behaviour was not fully taken into account in the design, the impact assessment, and the annual implementation of the plan (see also [2]).

Factors that may have contributed negatively to the achievement of the plan's objectives are:

- The plan has been difficult to administer, especially with regards to Articles 11, 12 and 13.

- It is difficult to evaluate whether groups of vessels qualify to operate under Articles 11 and 13. Moreover, an evaluation of the effectiveness of Article 13 is difficult.

- The plan had no explicit economic dimension or objectives; it has not been communicated explicitly how the industry, or society for that matter, would have to deal with reductions in revenues.

A more general flaw was highlighted [28] which potentially affects numerous fishery regulations. The flaw relates to defining vessel catch limits in terms of catch composition, i.e. as percentage of the vessel's total catch, instead of regulating the total catch of (in this case) cod caught by the fleet segments. 


\section{Ways forward - old problems - new problems - new solutions}

Some of the aspects identified above can be improved by, for example, the allocation of a total allowable catch of cod (landings plus discards) - in tonnes, not as a percentage of their catch - to each segment or vessel of the fleet. This would provide fishermen with a target that is directly measurable by them and relates well to fishing mortality on cod. Obviously, it would be necessary for this catch to be monitored to show that this had not been exceeded (similar to the current requirement under Article 11/13 criteria). Indications from the RACs are that they are prepared to consider such catch quotas, although at this stage it is unclear if all Member States are willing to take on the costs of the necessary compliance checks. Elsewhere it has been found that $100 \%$ observer coverage in combination with catch limits in the form of ITQs provided an incentive to change targeting behaviour in a mixed fishery [46]; recent developments in Europe involving CCTV and catch quotas may provide similar incentives. One key aspect of this approach is that it results in internalisation of the costs of fishing. In the current system with landings quotas, the cost of catching in excess of those quotas in terms of loss to the resource, is shared by everyone (fishers as well as the society at large, now as well as in the future), giving rise to the tragedy of the commons [20] where individual rational fishers do not experience an incentive to optimize targeting and minimize discarding. Catch quotas bring these costs back to the actor because the sanctions on overquota fishing are experienced directly at the level of the individual fisher and thus have to be taken into account into the fishers' business decisions; this will drive rational fishers to adjust their targeting behaviour to the agreed fishing opportunities [46]. Another possibility to achieve this would be to allocate quotas of 'fishing pressure credits' to fishers, with spatiotemporally varying tariffs (in effect, limiting effort in a spatiotemporally differentiated manner) [64, 65]. In this approach, agreed fishing opportunities are translated into a total amount of available credits, but fishers pay more credits per day from their quotas when fishing in high-abundance areas than when fishing in low-abundance areas; this way cod-avoidance is incentivised while retaining the fishers' flexibility $[64,65]$. Another possibility would be the payment of 'overquota landing tax', a system currently implemented in New Zealand, and explored for European stocks [66].

Apart from the flawed use of catch percentages as criterion, Article 13 is the most promising element of the plan for three reasons: (i) it follows the paradigm of participatory governance and results-based management; (ii) it has a direct relation to the objectives through controlling the actual catches; and (iii) it has the potential for finetuning of measures to specific fisheries. Nevertheless, its formal requirements (in its current form) to show that it delivers F reductions are problematic.

The requirements from a recovery plan need to be framed in terms of results-based management with a selection of measurable aspects that will show whether the chosen approach is achieving its objectives. A combination of metrics is required: in the shortterm (annually or within-year) performance should be monitored through metrics that focus on measurable changes in fisher behaviour (such as changes in catches, shifts in effort allocation to certain gears, métiers, areas and seasons in relation to cod 
concentrations), and for the medium-term, over several years, the effectiveness should be evaluated through metrics such as stock status and mortality. The evaluation of the effectiveness of the plan's measures probably has to be deferred a few years into the future, when more reliable estimates become available of stock status and of whether the intended reductions in $\mathrm{F}$ have actually occurred and the objectives been achieved. Currently, the HCR in the plan is overly reliant on annual estimates of F which are either absent, inaccurate or imprecise. Consideration should be given to multiannual metrics, such as mean F and SSB over the last 3 years, for informing decisions.

While fisheries managers are adjusting to the new paradigm of governance, results-based management, and reversal of the burden-of-proof, and its opportunities and limitations, another promising paradigm shift is happening: real-time high-resolution spatiotemporal data on vessel activity (VMS) and catches (electronic logbooks and fully documented fishing) are becoming available. These may allow for management measures to be set and tailored to specific fisheries at a finer spatiotemporal scale, such as the seasonal and realtime closures implemented under Article 13 (and new approaches proposed [e.g. 64]), than the grand-scale overall TACs and effort limitations which are based on rough largescale annual estimates at the level of the stock and the management area.

Drawing on the experiences of successful management regimes in other parts of the world and taking on board some of the lessons learnt from recent EU management plan experience, the further development of cod plans might usefully include the following considerations.

I. Through the implementation of catch quotas (landings plus discards) the fishers will experience internalisation of the costs of discarding, which they will then have to take into account in their business decisions. Catch quotas are also more directly related to the parameter of interest $(\mathrm{F})$ than landings quotas or catch composition percentages or broad-brush effort limits.

II. Through participatory governance, such as in Article 13, stakeholders are encouraged to phrase plans that suit their fishery practices, which will result in greater stakeholder buy-in and compliance. Such plans could include: locally organised schemes to give increased access where the impact on cod is the least; further technical development towards selective gear able to catch one or a few targeted species at a time, which would alleviate issues related to mixed fisheries and allow for a much easier management of the different sections of the fleet; flexibility at a fine spatiotemporal scale and at fisheryby-fishery level - with different options available to the individual fisher suited to the actual stock distribution and the fishing practices, which will help to prevent perverse incentives; explicit inclusion of mixed-fisheries issues at the local scale. All these plans would need monitoring in the short term to show that catches (landings and discards) of cod were in line with the allocated quotas. If these measures result in losses in revenue that have a serious impact these will need to be explicitly considered, otherwise the economic drivers will likely reduce the effectiveness of any control measures and discourage participation or uptake of more selective harvesting. 
III. The use of multiple metrics at different appropriate time-scales to estimate the performance and effectiveness of the management (e.g., catches, effort allocation to gears, métiers, areas and seasons at an annual or within-year time scale; stock-status parameters evaluated over a number of years) will help to evaluate whether the regulatory measures are achieving the stated objectives.

\section{Acknowledgements}

The first author is funded through a Fellowship (Grant-Aid Agreement No. PDOC/FS/07/002) funded by the Sea Change strategy with the support of the Marine Institute and the Marine Research Sub-programme of the National Development Plan 2007 - 2013, Ireland. Most of the analyses for this paper were undertaken in the context of the joint STECF-ICES expert group set with the task of evaluating the cod plan between February and June 2011.

\section{References}

[1] FAO. The State of World Fisheries and Aquaculture 2010. FAO Fisheries Department, Rome. 2010.

[2] Fulton EA, Smith ADM, Smith DC, Van Putten IE. Human behaviour: the key source of uncertainty in fisheries management. Fish and Fisheries. 2011;12:2-17.

[3] Gutiérrez NL, Hilborn R, Defeo O. Leadership, social capital and incentives promote successful fisheries. Nature. 2011;470:386-389.

[4] Hammer C, von Dorrien C, Hopkins CCE, Köster FW, Nilssen EM, St John M, et al. Framework of stock-recovery strategies: analyses of factors affecting success and failure. ICES Journal of Marine Science. 2010;67:1849-55.

[5] Murawski SA. Rebuilding depleted fish stocks: the good, the bad, and, mostly, the ugly. ICES Journal of Marine Science. 2010;67:1830-40.

[6] Wakeford RC, Agnew DJ, Mees CC. Review of institutional arrangements and evaluation of factors associated with successful stock recovery plans. Reviews in Fisheries Science. 2009;17:190-222.

[7] Butterworth DS. Why a management procedure approach? Some positives and negatives. ICES Journal of Marine Science. 2007;64:613-7.

[8] De Oliveira JAA, Kell LT, Punt AE, Roel BA, Butterworth DS. Managing without best predictions: the management strategy evaluation framework. In: Payne A, Cotter J, Potter T, editors. Advances in Fisheries Science 50 Years on from Beverton and Holt. Oxford: Blackwell Publishing; 2008. p. 104-34.

[9] Punt AE, Donovan GP. Developing management procedures that are robust to uncertainty: lessons from the International Whaling Commission. ICES Journal of Marine Science. 2007;64:603-12.

[10] FAO. Code of Conduct for Responsible Fisheries. FAO, Rome. 41 pp. 1998. [11] ICES. Report of the Study Group on Management Strategies (SGMAS). ICES CM 2006/ACFM:15. 2006.

[12] Ulrich C, Reeves SA, Vermard Y, Holmes SJ, Vanhee W. Reconciling singlespecies TACs in the North Sea demersal fisheries using the Fcube mixed-fisheries advice framework. ICES Journal of Marine Science. 2011;68:1535-47.

[13] Aps R, Lassen H. Recovery of depleted Baltic Sea fish stocks: a review. ICES Journal of Marine Science. 2010;67:1856-60. 
[14] Delaney AE, McLay HA, Van Densen WLT. Influences of discourse on decisionmaking in EU fisheries management: the case of North Sea cod (Gadus morhua). ICES Journal of Marine Science. 2007;64:804-10.

[15] Holden M. The Common Fisheries Policy: Origin, Evaluation, and Future. Fishing News Books, Oxford. 274 pp.1994.

[16] Rademeyer RA, Plagányi ÉE, Butterworth DS. Tips and tricks in designing management procedures. ICES Journal of Marine Science. 2007;64:618-25.

[17] ICES. Report of the Study Group on Management Strategies (SGMAS), 17-21

November 2008, Lisbon, Portugal. ICES CM 2008/ACOM:24. Diane. 74 pp. 2008.

[18] Hamon K, Ulrich C, Hoff A, Kell LT. Evaluation of management strategies for the mixed North Sea roundfish fisheries with the FLR framework. In: Oxley L, Kulasiri D, editors. MODSIM December 2007 International Congress on Modelling and Simulation. Modelling and Simulation Society of Australia and New Zealand2007. p. 2813-9.

[19] Hatcher A, Jaffry S, Bennett E. Normative and social influences affecting compliance with fishery regulations. Land Economics. 2000;76:448-61.

[20] Kraak SBM. Exploring the 'public goods game' model to overcome the Tragedy of the Commons in fisheries management. Fish and Fisheries. 2011;12:18-33.

[21] Kuperan K, Sutinen JG. Blue water crime: Deterrence, legitimacy, and compliance in fisheries. Law \& Society Review. 1998;32:309-37.

[22] Raakjær Nielsen J. An analytical framework for studying: compliance and legitimacy in fisheries management. Marine Policy. 2003;27:425-32.

[23] Raakjær Nielsen J, Mathiesen C. Important factors influencing rule compliance in fisheries lessons from Denmark. Marine Policy. 2003;27:409-16.

[24] Anonymous. Reform of the Common Fisheries Policy: Green Paper. European Commission. 2009. p. 24 p.

[25] Anonymous. Proposal for a regulation of the European parliament and of the council on the Common Fisheries Policy. Brussels, 1372011, COM(2011) 425 final, 2011/0195 (COD). 2011.

[26] DFO. Evaluation of the commercial groundfish pilot program. http://www.pac.dfompo.gc.ca/fm-gp/commercial/ground-fond/index-eng.htm. 2010. p. 29.

[27] Kindt-Larsen L, Kirkegaard E, Dalskov J. Fully documented fishery: a tool to support a catch quota management system. ICES Journal of Marine Science.

2011;68:1606-10.

[28] STECF. Evaluation of multi-annual plans for cod in Irish Sea, Kattegat, North Sea, and West of Scotland (STECF-11-07). Edited by John Simmonds and Sarah Kraak.

Luxembourg: Publications Office of the European Union. 2011.

[29] Eero M, Köster FWK, Vinther M. Why is the Eastern Baltic cod recovering? Marine Policy. 2012;36:235-40.

[30] ICES. Report of the Working Group for Celtic Seas Ecoregion (WGCSE), 11-19

May 2011, Copenhagen, Denmark. ICES CM 2011/ACOM:12. 1573 pp. 2011.

[31] ICES. Report of the Working Group on the Assessment of Demersal Stocks in the North Sea and Skagerrak (WGNSSK), 4 - 10 May 2011, Copenhagen, Denmark. ICES CM 2011/ACOM:13. 1197 pp. 2011.

[32] STECF. Evaluation of Fishing Effort Regimes Regarding Annexes IIA, IIB and IIC of TAC \& Quota Regulations, Celtic Sea and Bay of Biscay (STECF-11-13) Edited by 
Nick Bailey \& Nikolaos Mitrakis. Luxembourg: Publications Office of the European Union. 2011.

[33] Needle CL, Catarino R. Evaluating the effect of real-time closures on cod targeting. ICES Journal of Marine Science. 2011;68:1647-55.

[34] Holmes SJ, Bailey N, Campbell N, Catarino R, Barratt K, Gibb A, et al. Using fishery-dependent data to inform the development and operation of a co-management initiative to reduce cod mortality and cut discards. ICES Journal of Marine Science. 2011;68:1679-88.

[35] STECF. 34th Plenary Meeting Report of the Scientific, Technical and Economic Committee for Fisheries (PLEN-10-02). Luxembourg: Publications Office of the European Union. 2010.

[36] STECF. 37th Plenary Meeting Report of the Scientific, Technical and Economic Committee for Fisheries (PLEN-11-02). Plenary Meeting, 11-15 July 2011, Copenhagen. Edited by John Casey and Hendrik Doerner. 2011.

[37] Holmes SJ, Fryer RJ. Significance of seal feeding on cod west of Scotland - results from a state space stock assessment model. ICES CM 2011/I:22. 2011.

[38] ICES. Report of the Working Group on the Assessment of Demersal Stocks in the North Sea and Skagerrak (WGNSSK), 6-12 May 2009, Copenhagen, Denmark. ICES Document CM 2009/ACOM:10. 2009.

[39] ICES. Report of the Working Group on the Assessment of Demersal Stocks in the North Sea and Skagerrak (WGNSSK), 5 -11 May 2010, Copenhagen, Denmark. ICES CM 2010/ACOM:13. 1058 pp. 2010.

[40] ICES. Report of the ICES Advisory Committee 2008. ICES Advice, 2008. Book 6, 326 pp. 2008.

[41] Kraak SBM, Kelly CJ, Codling EA, Rogan E. On scientists' discomfort in fisheries advisory science: the example of simulation-based fisheries management-strategy evaluations. Fish and Fisheries. 2010;11:119-32.

[42] de la Mare WK. Simulation studies on management procedures. Reports of the International Whaling Commission, 36: 429-450. 1986.

[43] Butterworth DS, Bentley N, De Oliveira JAA, Donovan GP, Kell LT, Parma AM, et al. Purported flaws in management strategy evaluation: basic problems or misinterpretations? ICES Journal of Marine Science. 2010;67:567-74.

[44] ICES. Report of the Working Group on Mixed Fisheries Advice for the North Sea (WGMIXFISH), 31 August - 3 September 2010, ICES Headquarters, Copenhagen, Denmark. ICES CM 2010/ACOM:35 93 pp. 2010.

[45] ICES. Report of the Working Group on Mixed Fisheries Advice for the North Sea (WGMIXFISH), 29 August - 2 September 2011. ICES CM 2011/ACOM:22. 2011.

[46] Branch TA, Hilborn R. Matching catches to quotas in a multispecies trawl fishery: targeting and avoidance behavior under individual transferable quotas. Canadian Journal of Fisheries and Aquatic Sciences. 2008;65:1435-46.

[47] Kraak SBM, Buisman FC, Dickey-Collas M, Poos JJ, Pastoors MA, Smit JGP, et al. The effect of management choices on the sustainability and economic performance of a mixed fishery: a simulation study. ICES Journal of Marine Science. 2008;65:697-712. [48] Poos JJ, Rijnsdorp AD. The dynamics of small scale patchiness of plaice and sole as reflected in catch rates of the Dutch beam trawl fleet and its implications for the fleet dynamics. Journal of Sea Research. 2007;58:100-12. 
[49] Quirijns FJ, Poos JJ, Rijnsdorp AD. Standardizing commercial CPUE data in monitoring stock dynamics: accounting for targeting behaviour in mixed fisheries. Fisheries Research. 2008;89:1-8.

[50] Rijnsdorp AD, Daan N, Dekker W. Partial fishing mortality per fishing trip: a useful indicator of effective fishing effort in mixed demersal fisheries. ICES Journal of Marine Science. 2006;63:556-66.

[51] van Oostenbrugge H, Powell JP, Smit JPG, Poos JJ, Kraak SBM, Buisman EFC.

Linking catchability and fisher behaviour under effort management. Aquatic Living

Resources. 2008;21:265-73.

[52] Harley SJ, Myers RA, Dunn A. Is catch-per-unit-effort proportional to abundance?

Canadian Journal of Fisheries and Aquatic Sciences. 2001;58:1760-72.

[53] STECF. 32nd Plenary Meeting Report of the Scientific, Technical and Economic

Committee for Fisheries (PLEN-09-03). Luxembourg: Publications Office of the European Union. 2009.

[54] ICES. Report of the Ad hoc Group on Cod Recovery Management Plan (AGCREMP), 18-19 August 2008, Copenhagen, Denmark. ICES CM 2008/ACOM:61. 83 pp. 2009.

[55] ICES. Report of the Working Group on the Celtic Seas Region (WGCSE), 13 -19

May 2009, Copenhagen, Denmark. ICES CM 2009/ACOM:09. 1430 pp. 2009.

[56] ICES. Report of the ICES Advisory Committee 2009. ICES Advice, 2009. Book 6, 236 pp. 2009.

[57] NSRAC. The North Sea Regional Advisory Council Demersal Working Group

Paper; Summary of Symposium on Cod Recovery 9th and 10th of March 2007

Edinburgh, Scotland http://www.acsfilmfest.co.uk/nsrac/wp-

content/uploads/2009/09/wp04a_wd20070411_Cod_Symposium_summary.pdf. 2007.

[58] Anonymous. Commission of the European Communities. Proposal for a Council

Regulation amending Regulation (EC) No 423/2004 as regards the recovery of cod stocks and amending Regulation (EEC) No 2847/93. \{SEC(2008) 386\} \{SEC(2008) 389\}.

Brussels, 2.4.2008 COM(2008) 162 final. 2008/0063 (CNS). 2008.

[59] NSRAC. The North Sea Regional Advisory Council Review of the Cod Recovery

Plan Response to the Commission's Non Paper on Cod Recovery.

http://www.acsfilmfest.co.uk/nsrac/wp-

content/uploads/2009/09/ex20071015_Agreed_Cod_Recovery.pdf. 2007.

[60] NSRAC. The North Sea Regional Advisory Council. NSRAC Position Paper; On the Commission's Proposal for a Council Regulation amending Regulation (EC) No

423/2004 as regards the recovery of cod stocks and amending Regulation (EEC) No

2847/93. http://www.acsfilmfest.co.uk/nsrac/wp-

content/uploads/2009/08/ex20080630_Position_Amending_regs_cod_recovery.pdf. 2008.

[61] NWWRAC. North Western Waters Regional Advisory Council; position paper;

Considerations of the NWWRAC in response to the NSRAC-NWWRAC Joint

Symposium in Edinburgh and the review of the EU Cod Recovery Plan.

http://www.nwwrac.org/admin/publication/upload/NWWRAC_\%20Position_\%20Paper_ Cod_\%20Recovery.pdf.pdf. 2007.

[62] NWWRAC. Response of the North Western Waters Regional Advisory Council to the Commissions Non paper on Cod Recovery. 
http://www.nwwrac.org/admin/publication/upload/NWWRAC\%20Response $\% 20$ to $\% 20$ th e\%20Commission\%20Non-paper\%20on\%20Cod\%20Recovery\%20Final\%20EN.pdf. 2007.

[63] Kelly CJ, Codling EA, Rogan E. The Irish Sea cod recovery plan: some lessons learned. ICES Journal of Marine Science. 2006;63:600-10.

[64] Kraak SBM, Reid DG, Gerritsen HD, Kelly CJ, Fitzpatrick M, Codling EA, et al. 21st century fisheries management: A spatiotemporally explicit tariff-based approach combining multiple drivers and incentivising responsible fishing. ICES Journal of Marine Science. 2012;69(4):590-601.

[65] Rijnsdorp AD, Daan N, Dekker W, Poos JJ, Van Densen WLT. Sustainable use of flatfish resources: Addressing the credibility crisis in mixed fisheries management.

Journal of Sea Research. 2007;57:114-25.

[66] Marchal P, Little LR, Thébaud O. Quota allocation in mixed fisheries: a

bioeconomic modelling approach applied to the Channel flatfish fisheries. ICES Journal of Marine Science. 2011;68:1580-91.

[67] ICES. Report of the Baltic Fisheries Assessment Working Group (WGBFAS), 12 19 April 2011, Copenhagen, Denmark. ICES CM 2011/ACOM:10. 824pp. 2011.

[68] ICES. Report of the ICES Advisory Committee 2011. ICES Advice, 2011. Book 5. 2011.

[69] ICES. Report of the ICES Advisory Committee 2011. ICES Advice, 2011. Book 6. 2011. 


\section{Figures}
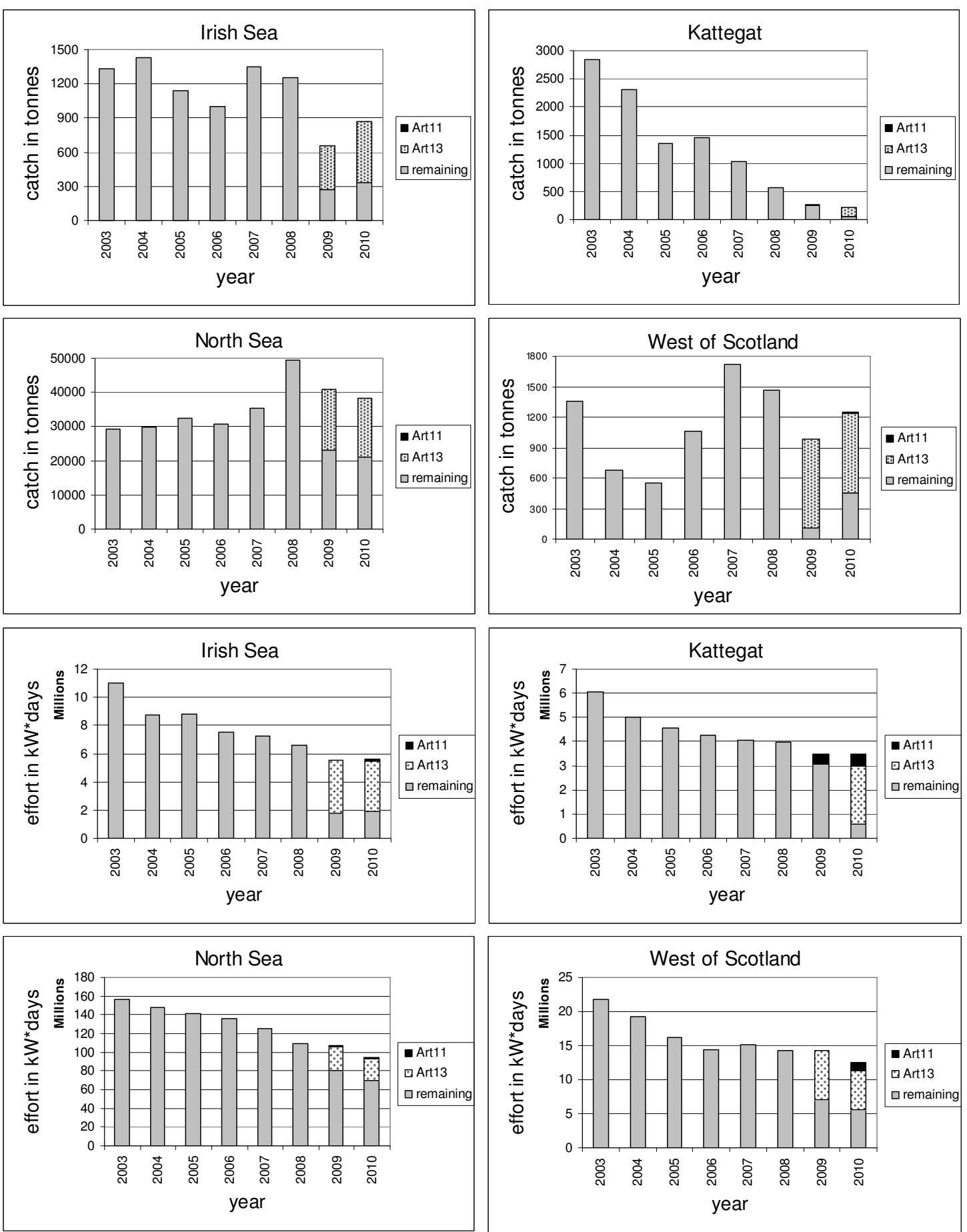

Figure 1. Time series for the four cod stocks. Catch is pictured for regulated and unregulated gear, where catch taken by vessels operating under Articles 11 and 13 respectively is displayed separately. Catch refers to landings and discards as raised by procedures outlined in [32]. Effort is pictured for all regulated gear only, where effort by vessels operating under Articles 11 and 13 respectively is displayed separately. 


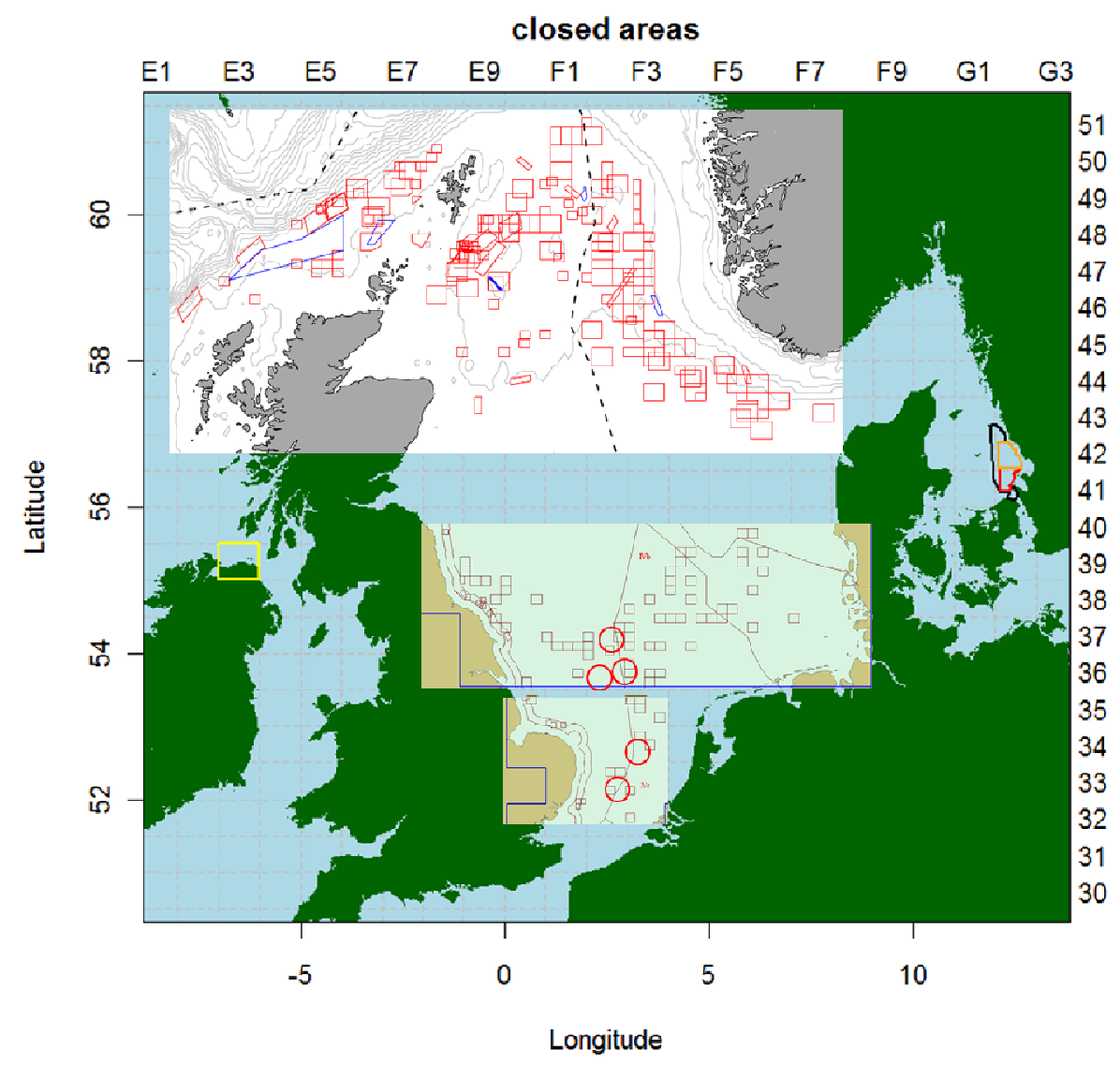

Figure 2. The location of permanent, seasonal, and real-time closures. The yellow rectangle (in ICES division VIa on the northern coast of Northern Ireland) represents the seasonal closure that the Irish authorities have introduced, closed from 1 October to 31 March to all Irish vessels, irrespective of fishing method. This period coincides with peak cod catches. The red polygons (in ICES divisions VIa and IVa to the north and northeast of Scotland) represent the RTCs in 2010 under the Scottish Conservation Credits Scheme; blue polygons in the same area represent other closures directed at protecting cod. The red circles and the grey rectangles (in ICES divisions IVb, IVc and VIId; the North Sea) represent the UK closures during 2010: 5 seasonal closures (red circles), 3 of one month and 2 of four months in duration covering spawning locations for North Sea cod; 105 real time closures (grey rectangles), with 82 in offshore areas of $7.5 \times 8.5$ miles closed for 1 month, and 20 in inshore areas of $6.5 \times 3.5$ miles closed for 14 days, based on lpue records; as well as 3 areas of $7.5 \times 8.5$ miles closed for 21 days for the protection of juvenile cod, identified on the basis of live sampling. The black, orange, and red shapes (in ICES area IIIa, Kattegat) represent the Danish and Swedish spatial closures in Kattegat and the Northern part of the Sound. The "black" area is closed during the 1st January-31st March (spawning season), except for fisheries with selective gears with a very low catch of cod; The "black" area in the Northern Sound ("Kilen" or the triangle) is closed 1st February-31st March, except for fisheries with selective gears; The "orange" area is closed for all fisheries except fisheries with selective gears. The "red" area is closed for all fisheries, including recreational fisheries. 

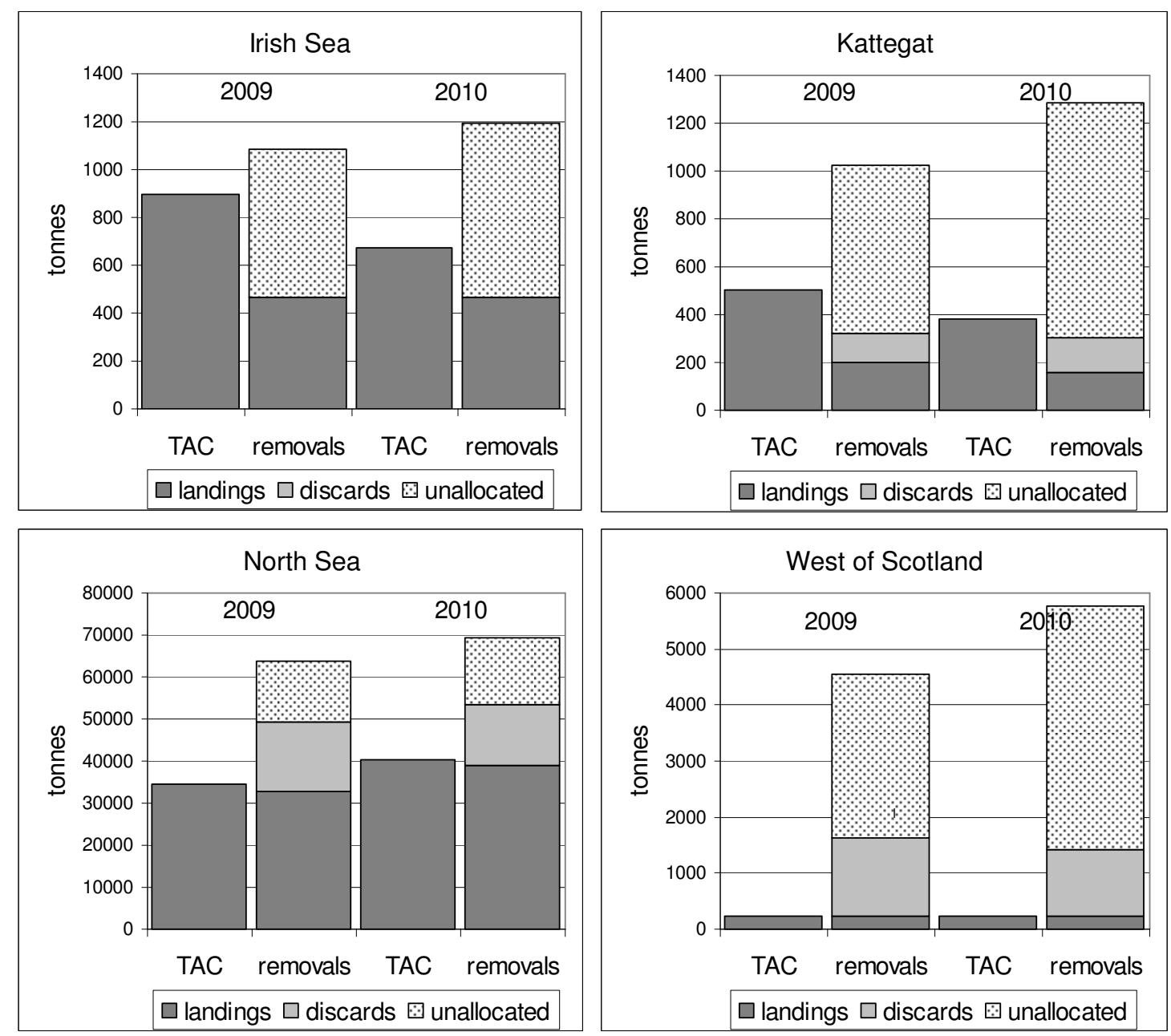

Figure 3. Agreed TACs and removals in 2009 and 2010 for the four cod stocks. Unallocated removals are estimated by the assessment model as removed fish in excess of observed catches and assumed natural mortality. For the assessments of the North Sea and West of Scotland stocks the observed catches have a reported landings and a discards component (the discards component is derived through a raising procedure from observed trips). For the assessments of the Irish Sea and the Kattegat the catches include only reported landings, while no raised observed discards are included; thus, in these cases the model estimates of unallocated removals may include discards. In the case of the Kattegat stock discard estimates (which were not used in the assessment) are available, and for this figure subtracted from the unallocated removals (so that total removals are, in all cases, removals above assumed natural mortality). Thus, note that the 'absence' of discards in the figure for the Irish Sea stock does not imply that there are no discards, but just that they have not been estimated separately. In all cases, the unallocated removals may include unobserved or non-estimated discards, additional natural mortality, or may be due to model misspecification. Information is from [30, 67-69]. 


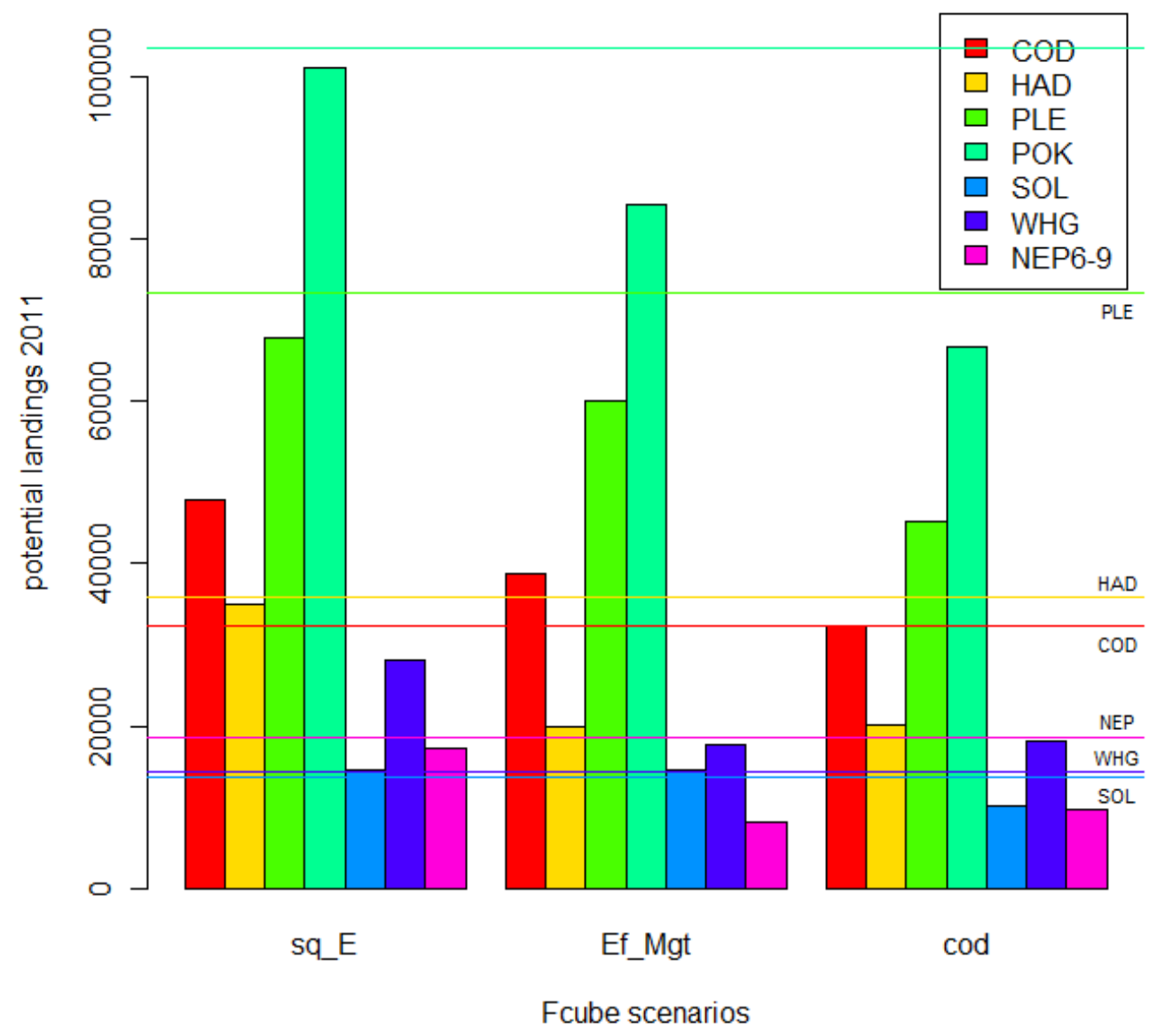

Figure 4. Potential landings (i.e. the marketable component of the catch, as opposed to discards) in 2011 by stock, as estimated from a two-years Fcube mixed-fisheries shortterm forecast, as in the stock-assessment year 2010. Three scenarios are displayed:

"Sq_E": the effort by fleet in 2010 and 2011 was set as equal to the effort in the latest data year (2009). "cod": The underlying assumption was that all fleets set their effort at the level corresponding to their cod quota share both in 2010 and 2011, regardless of other stocks. "Ef_Mgt": The effort in métiers that used gear controlled by the EU effort management regime had effort adjusted according to the cod plan. In 2010, that implies a 13.3\% effort reduction in TR1 and TR2 gear categories compared to 2009, and another $15.4 \%$ reduction in 2011 compared to 2010 . Coloured horizontal lines correspond to the landings estimated from the single species forecast. See [12] for more explanation. 